\title{
Effect of ultrasonic and thermal disintegration of water treatment sludge
}

\author{
Justyna Górka ${ }^{1, *}$, Małgorzata Cimochowicz-Rybicka ${ }^{1}$, and Beata Fryźlewicz-Kozak ${ }^{2}$ \\ ${ }^{1}$ University of Technology, Department of Environmental Engineering, 24 Warszawska, Cracow \\ 31-155, Poland \\ ${ }^{2}$ University of Technology, Department of Chemical Engineering and Technology, 24 Warszawska, \\ Cracow 31-155, Poland
}

\begin{abstract}
This research was conducted to evaluate the effects of thermal and ultrasound disintegration on the disintegration degree (DD) of water treatment sludge from a municipal water treatment plant. A disintegration process was used to (i) improve subsequent coagulation efficiencies and dewatering processes (ii) reduce sludge production, and (iii) obtain both economic and enviromental benefits. The results show that using the disintegration process has an influence on DD values. It is also worth emphasising that the main parameter determining the efficiency of ultrasonic and thermal disintegration was the time of the applied process. Other parameters such as ultrasound intensity and temperature had a reduced impact on DD values.
\end{abstract}

\section{Introduction}

Water treatment sludge produced in the water treatment processes is an economic and environmental problem. The volumes of sludge produced is increasing due to increasing volumes of water being treated (sludge volumes typically ranging from 2 to $5 \%$ of treated water) [1]. Environmental concerns mean there are ongoing effort to limit formation and improve disposal of this type of waste. Therefore, the management and disposal of water treatment sludge is a very important problem related to water treatment.

The water treatment sludge characterised by the content of organic and inorganic compounds. Its composition and properties depend on the quality of raw water, the water Surface water is characterised by its variable composition and this can cause, the formation of sludge with large quantitative and qualitative differences [2]. Thus water treatment sludge has to be 'individually' treated for each water treatment plant, especially in terms of possibilities for subsequent disposal. There are many ways to dispose and reuse of water treatment sludge including [2-4]:

- Coagulant recovery and reuse,

- As coagulant in wastewater treatment,

- As adsorbent for contaminants and heavy metals wastewater,

- As substrate in constructed wetlands,

\footnotetext{
* Corresponding author: justynagrka@gmail.com
} 
- In sewage sludge dewatering,

- In cement production,

- In manufacturing lightweight aggregates,

- In brick and ceramic production,

- As raw material for concrete and mortar,

- In agricultural practice and other land based uses.

Disintegrated water treatment sludge has many applications. Zhou et al., (2015) [5] focused on the use of water treatment sludge during flocculation and dewatering of sewage sludge. In addition, they used ultrasonic disintegration of water treatment sludge to increase the efficiency of these processes, especially to improve subsequent coagulation efficiencies, reduce sludge production, and obtain both economic and enviromental benefits. Other work has described the use of disintegrated water treatment sludge during anaerobic co-digestion of sewage sludge [6]. Studies have shown that using disintegrated water treatment sludge during anaerobic digestion of sewage sludge increases the biogas production by about $20 \%$ (especially using thermal method) compared to samples without disintegration [7]. The influence of disintegrated water treatment sludge on the sewage sludge dewatering was also investigated [8]. Analysis shows that thermal and ultrasonic disintegration of water treatment sludge did not significantly affect sewage sludge dewaterability. However there is still an incomplete understanding of the mechanisms of influencing disintegration of water treatment sludge. This article investigated the impact of water treatment sludge disintegration on the disintegration degree (DD). The DD determines the effectiveness and amount of released organic substance (expressed in chemical oxygen demand (COD)) during disintegration process.

Table 1 shows the disintegration methods. Choosing the adequate disintegration method is challenging, because there is a constant development of research on the application of these techniques. Recently, many research works are focused on the using of a combination of different disintegration processes, such as alkaline-ultrasound, electrical-alkali, ultrasound-ozonation, microwave- $\mathrm{H}_{2} \mathrm{O}_{2}$ and thermal- $\mathrm{NaOH}$ [9].

It is also difficult to choose appropriate criterion for choosing the correct disintegration process. In addition, each of the available methods has advantages, but they may also have limitations. In practice, the possibilities of implementing sludge disintegration methods are limited to techniques which score highly during purely technical evaluation and the implementation and operation costs. These techniques include thermal and mechanical methods [10]. Therefore, during the tests used two disintegration methods; (i) ultrasonic (mechanical) and (ii) thermal.

Table 1. Disintegration methods.

\begin{tabular}{|c|c|c|c|}
\hline Mechanical & Chemical & Biological & Thermal \\
\hline - Ultrasounds & - Hydrolysis & -Enzymes & - Low temperature \\
\hline & with alkal1 & & $\left(<100^{\circ} \mathrm{C}\right)$ \\
\hline - Hydrodynamic & - Acid & - Autolysis & - High temperature \\
\hline & hydrolysis & & $\left(>100^{\circ} \mathrm{C}\right)$ \\
\hline - Homogenization & -Ozonation & -Mushrooms, & -Freezing, \\
\hline - Contrifugal & - Fenton reaction & & \\
\hline disintegration & & & \\
\hline - Electrical impulse & & & \\
\hline - Ball mill & & & \\
\hline
\end{tabular}




\section{Material and methods}

\subsection{The water treatment sludge characteristics}

The water treatment sludge came from a municipal water treatment plant with a capacity of $100,000 \mathrm{~m}^{3} \cdot \mathrm{d}^{-1}$. The sludge was produced during coagulation of water with aluminium coagulant (PAX). DD analysis was performed for two samples (collected from water treatment plant in winter and summer periods) in triplicate. The physic-chemical characteristics of water treatment sludge are shown in the Table 2.

Table 2. Physic-chemical characteristics of water treatment sludge.

\begin{tabular}{|l|l|c|c|}
\hline \multirow{2}{*}{ Parameter } & \multicolumn{2}{c|}{ Water treatment sludge } \\
\cline { 3 - 4 } & {$[-]$} & 6.84 & 6.70 \\
\hline $\mathrm{pH}$ & {$\left[\mathrm{g} \cdot \mathrm{dm}^{-3}\right]$} & 34.92 & 35.70 \\
\hline Dry matter & {$\left[\mathrm{gTVS} \cdot \mathrm{dm}^{-3}\right]$} & 9.75 & 9.98 \\
\hline Dry organic matter & {$\left[\mathrm{mgO}_{2} \cdot \mathrm{dm}^{-3}\right]$} & 6210 & 7945 \\
\hline COD & {$\left[\mathrm{mgO}_{2} \cdot \mathrm{dm}^{-3}\right]$} & 75 & 120 \\
\hline Soluble COD &
\end{tabular}

\subsection{Apparatus}

\subsubsection{Ultrasonic disintegration}

The ultrasonic energy source was the ultrasonic generator, type UD 11, with a piezoelectric transducer with a resonant frequency $(f)=22 \mathrm{kHz}$, with variable ultrasound intensity (I) ranging from $24-64 \cdot 10^{3} \mathrm{~W} / \mathrm{m}^{2}$, which corresponded to the amplitudes $(A)$ and ultrasound densities $\left(\varepsilon^{*}\right)$ shown in Table 3 . The intensity of ultrasonic surface, produced by the UD-11 disintegrator was measured using the using the thermoelectric method and for comparison at the Tele- and Radiochemistry Institute in Warsaw, using measure cavitation intensity produced by Branson. The sonotrode diameter was $0.02 \mathrm{~m}$. The experiments were carried out for different sonication times $t=(3-7 \mathrm{~min})$. The volume of a single sample was $130 \mathrm{~cm}^{3}$ with a 0.03 sonotrode submerged.

Table 3. Variable parameters of the applied ultrasound energy.

\begin{tabular}{|c|c|c|}
\hline $\begin{array}{c}\mathbf{I} \cdot \mathbf{1 0}^{-3} \\
{\left[\mathbf{W} / \mathbf{m}^{\mathbf{2}}\right]}\end{array}$ & $\begin{array}{c}\mathbf{A} \cdot \mathbf{1 0}^{\mathbf{6}} \\
{[\mathbf{m}]}\end{array}$ & $\begin{array}{c}\boldsymbol{\varepsilon}^{*} \cdot \mathbf{1 0}^{-\mathbf{4}} \\
{\left[\mathbf{W} / \mathbf{m}^{3}\right]}\end{array}$ \\
\hline 24 & 2.9 & 7.536 \\
\hline 34 & 5.8 & 10.676 \\
\hline 44 & 8.9 & 13.816 \\
\hline 64 & 14.5 & 20.096 \\
\hline
\end{tabular}

\subsubsection{Thermal disintegration}

The thermal disintegration of the water treatment sludge was carried out in a water bath with heating and a magnetic stirrer for each sample. The experiments were carried out for 
different pasteurization times $t=(15-60 \mathrm{~min})$. The pasteurization temperature was $55-70^{\circ} \mathrm{C}$, with a sample volume of $130 \mathrm{~cm}^{3}$.

\subsection{The disintegration degree calculation}

The DD was determined based on the measurement of the maximum COD value achievable as a result of release using alkaline hydrolysis (parameter $\left.\mathrm{COD}_{3}\right)[11,12]$ :

$$
D D=\frac{C O D_{1}-C O D_{2}}{C O D_{3}-C O D_{2}} \times 100 \%
$$

where:

$D D$ - disintegration degree [\%],

$C O D_{1}-\mathrm{COD}$ in the supernatant water in sample after disintegration $\left[\mathrm{mg} \mathrm{O}_{2} \cdot \mathrm{dm}^{-3}\right]$,

$C O D_{2}-\mathrm{COD}$ in the supernatant water in sample without disintegration $\left[\mathrm{mg} \mathrm{O}_{2} \cdot \mathrm{dm}^{-3}\right]$,

$\mathrm{COD}_{3}-\mathrm{COD}$ in the supernatant water in sample after chemical disintegration $(1 \mathrm{M} \mathrm{NaOH}$ after 22 hours in $20^{\circ} \mathrm{C}$ ) $\left[\mathrm{mg} \mathrm{O}_{2} \cdot \mathrm{dm}^{-3}\right]$.

Statistical analysis was carried out using MS Excel. In order to investigate the significance of the regression relationship between disintegration parameters and the degree of disintegration, the t-Student's correlation coefficient was used, assuming a significance level of $\alpha=0.05$. The normality of the distribution was examined using the Shapiro-Wilk test $(\alpha=0.10)$ [13].

\section{Results}

The examination of the disintegration degree of ultrasonic and thermal disintegration was performed for water treatment sludge samples according to the method described in Section 2. Table 4 shows the measurement results taking into account parameter changes.

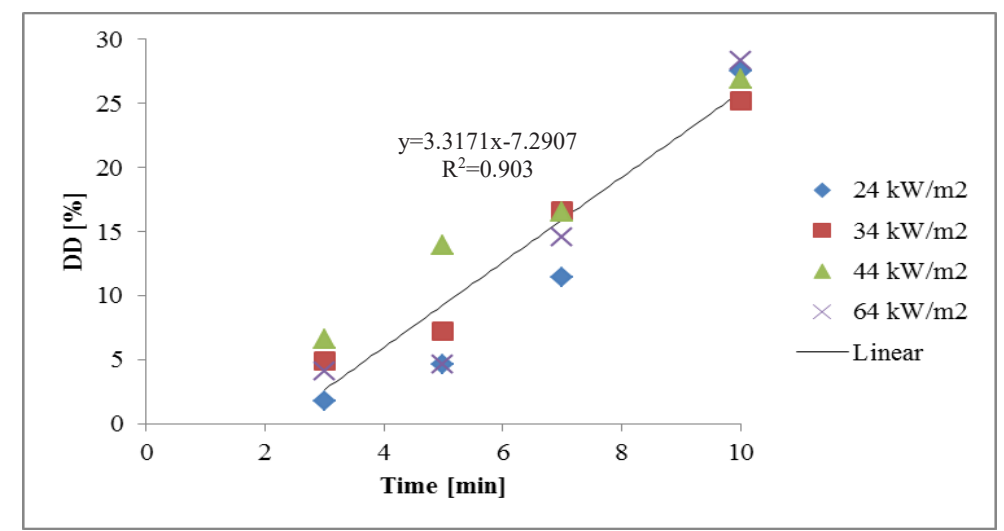

Fig. 1. Impact of sonication time on the DD values of water treatment sludge.

Figure 1 shows the impact of sonication time on the DD. With variable sonication time from 3 to 10 minutes and ultrasound intensity form 24 to $64 \mathrm{~kW} \cdot \mathrm{m}^{-2}$, the regression relationship was in the form of: 
Value of correlation coefficient $(R)$ equal 0.9503 was statistically significant (normal distribution, the value of statistics $t=11.42$ at the significance level $\alpha=0.05$, $\left.I=\left(-\infty,-2.145>_{v}<2.145,+\infty\right)\right)$. Determination of the pasteurization time impact on the DD is illustrated in Figure 2 . At the variable time $(15 \mathrm{~min}-60 \mathrm{~min})$ and temperature $\left(55^{\circ} \mathrm{C}-70^{\circ} \mathrm{C}\right)$. It was observed that $R=0.9192$ was statistically significant (normal distribution, the value of statistics $t=8.73$, at the significance level $\left.\alpha=0.05, I=\left(-\infty,-2.145>_{\mathcal{v}}<2.145,+\infty\right)\right)$.

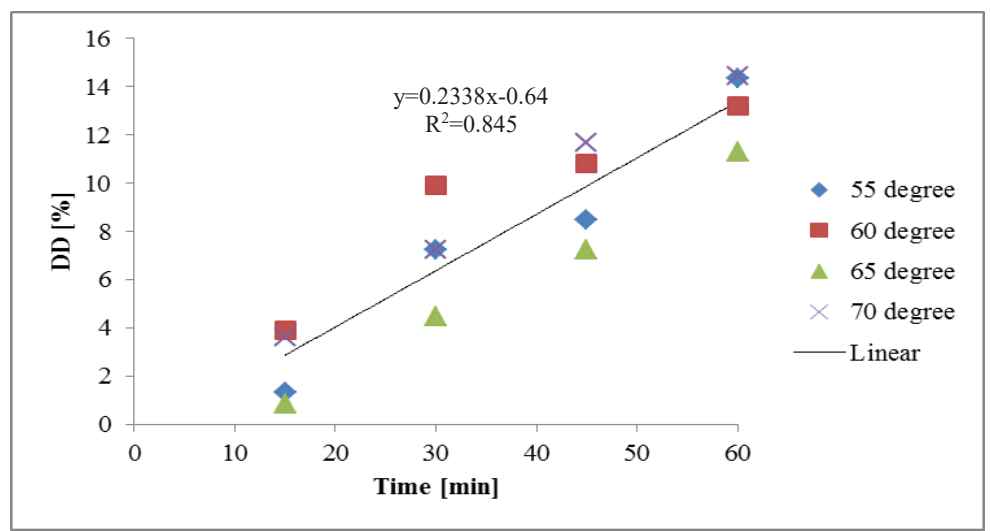

Fig. 2. Impact of pasteurization time on the DD values of water treatment sludge.

Table 4. The average DD values for water treatment sludge after ultrasonic and thermal disintegration.

\begin{tabular}{|c|c|c|c|c|c|}
\hline \multicolumn{6}{|c|}{ Ultrasonic disintegration } \\
\hline \multirow{3}{*}{\multicolumn{2}{|c|}{ Parameters }} & \multicolumn{4}{|c|}{ Time } \\
\hline & & $3 \min$ & $5 \min$ & $7 \mathrm{~min}$ & $10 \mathrm{~min}$ \\
\hline & & \multicolumn{4}{|c|}{$\mathrm{DD}[\%]$} \\
\hline \multirow{4}{*}{ 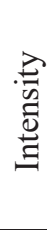 } & $24 \mathrm{~kW} \cdot \mathrm{m}^{-2}$ & 1.74 & 4.66 & 11.43 & 27.51 \\
\hline & $34 \mathrm{~kW} \cdot \mathrm{m}^{-2}$ & 4.94 & 7.20 & 16.63 & 25.25 \\
\hline & $44 \mathrm{~kW} \cdot \mathrm{m}^{-2}$ & 6.63 & 13.97 & 16.51 & 26.95 \\
\hline & $64 \mathrm{~kW} \cdot \mathrm{m}^{-2}$ & 4.09 & 4.66 & 14.53 & 28.36 \\
\hline \multicolumn{6}{|c|}{ Thermal disintegration } \\
\hline \multirow{3}{*}{\multicolumn{2}{|c|}{ Parameters }} & \multicolumn{4}{|c|}{ Time } \\
\hline & & $15 \mathrm{~min}$ & $30 \mathrm{~min}$ & $45 \mathrm{~min}$ & $60 \mathrm{~min}$ \\
\hline & & \multicolumn{4}{|c|}{$\mathrm{DD}[\%]$} \\
\hline \multirow{4}{*}{ 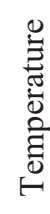 } & $55^{\circ} \mathrm{C}$ & 1.33 & 7.22 & 8.46 & 14.35 \\
\hline & $60^{\circ} \mathrm{C}$ & 3.90 & 9.89 & 10.84 & 13.21 \\
\hline & $65^{\circ} \mathrm{C}$ & 0.86 & 4.47 & 7.22 & 11.31 \\
\hline & $70^{\circ} \mathrm{C}$ & 3.61 & 7.22 & 11.69 & 14.45 \\
\hline
\end{tabular}

Interpretation of the form of the regression function in both cases indicated a linear relationship between time and disintegration degree. With increasing time, an increase in the DD of water treatment sludge was observed. Considering the ultrasonic disintegration, 
changes in ultrasound intensity did not cause differences in the DD values. The changes in temperature during thermal disintegration also had a small effect on DD.

It can be concluded that the main parameter determining the efficiency of ultrasonic and thermal disintegration is the time of process. The intensity of ultrasounds and temperature had less impact on DD. The longer disintegration time resulted in an increase the DD of the water treatment sludge. Due to the incomplete understanding of the complex mechanism of the impact of disintegration methods on water treatment sludge, further research is needed in relation to the use of disintegrated sludge in other processes (for example flocculation, anaerobic fermentation or dewatering of sewage sludge).

\section{Conclusions}

This research was conducted to elucidate the effects of ultrasound and thermal disintegration on the disintegration degree of water treatment sludge. The main conclusions were as follows:

1. The main parameter determining the efficiency of ultrasonic and thermal disintegration was the time of the disintegration process. Longer time increased the disintegration degree.

2. The intensity of ultrasounds during the ultrasonic disintegration of water treatment sludge had a little effect on the disintegration degree. The same conclusions can be drawn based on the thermal disintegration process - disintegration temperature had a little effect on the disintegration degree as well.

3. Due to incomplete understanding of the mechanism of the influence of disintegration methods on water treatment sludge, further research on this issue is necessary.

\section{References}

1. S. Szerzyna. Mat. Konf. Eko-Dok 609 (2013)

2. M. Kyncl, S. Cihalova, M. Jurkova, S. Langarova. Inż. Min. 11 (2012)

3. T. Ahmad, K. Ahmad, M. Alam. Jour. Clean. Prod. 124, 1 (2016)

4. K.B. Dassanayake, A. Surapanemi, C. Hetherington. Was. Man. 38, 321 (2015)

5. Z. Zhou., Y. Yang, X. Li, Y. Zhang, X. Guo. Ult. Son. 24, 19 (2015)

6. J. Górka, M. Cimochowicz-Rybicka. Env. Engin. 123 (2016)

7. M. Cimochowicz-Rybicka, J. Górka. Przem. Chem. 8 (2017)

8. J. Górka, M. Cimochowicz-Rybicka, M. Kryłów. E3S Web of Con. 30 (2018)

9. G. Zhen, X. Lu, H. Kato, Y. Zhao, Y.Y. Li. Ren. and Sus. En. Rev. 69 (2017)

10. K. Iskra, S. Miodoński. Mat. Konf. Eko-Dok 326 (2014)

11. M. Cimochowicz-Rybicka. Akt. Met. Osad. Śc. Zast. Ult. Dez. (2013)

12. E. Zielewicz-Madej. Otw. Sem. Akus. OSA 691 (2007)

13. W. Krysicki, J. Bartos, W. Dyczka, K. Królikowska, M. Wasilewski. Rach. Prawd. Stat. Mat. Zad. (1999) 